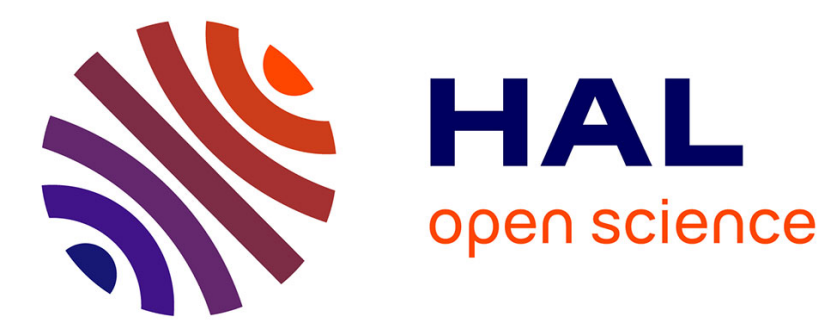

\title{
Adaptationism for Human Cognition: Strong, Spurious or Weak?
}

Scott Atran

\section{To cite this version:}

Scott Atran. Adaptationism for Human Cognition: Strong, Spurious or Weak?. Mind and Language, 2004. ijn_00000436

\section{HAL Id: ijn_00000436 \\ https://hal.science/ijn_00000436}

Submitted on 17 Dec 2003

HAL is a multi-disciplinary open access archive for the deposit and dissemination of scientific research documents, whether they are published or not. The documents may come from teaching and research institutions in France or abroad, or from public or private research centers.
L'archive ouverte pluridisciplinaire HAL, est destinée au dépôt et à la diffusion de documents scientifiques de niveau recherche, publiés ou non, émanant des établissements d'enseignement et de recherche français ou étrangers, des laboratoires publics ou privés. 
Mind and Language, in press

\title{
Adaptationism for Human Cognition: Strong, Spurious or Weak?
}

Scott Atran

satran@umich.edu

\begin{abstract}
(word count 100)
Strong adaptationists explore complex organic design as task-specific adaptations to ancestral environments. Its strategy seems best when there is evidence of homology. Weak adaptationists don't assume that complex organic (including cognitive and linguistic) functioning necessarily or primarily represents task-specific adaptation. Its approach to cognition resembles physicists' attempts to deductively explain the most facts with fewest hypotheses. For certain domain-specific competencies (folkbiology) strong adaptationism is useful but not necessary to research. With group-level belief systems (religion) strong adaptationism degenerates into spurious notions of social function and cultural selection. In other cases (language, especially universal grammar) weak adaptationism's "minimalist" approach seems productive.
\end{abstract}

Acknowledgements. Thanks to Noam Chomsky, Dan Sperber, Douglas Medin, David Hull, Steven Pinker, Peter Carruthers and the anonymous reviewers for critical arguments and generous suggestions on earlier drafts, and to Marc Hauser, Leda Cosmides, Justin Leiber and Clark Barrett for leads to information and sources. 
Address for correspondence: (Before June 1, 2004) Institute for Social Research, The University of Michigan, 426 Thompson St., Ann Arbor, MI 48106-1248; (after June 1, 2004) 9 Rampe de l'Observatoire, 66660 Port Vendres, France.

Word count: 12,750 
1. Introduction. In a sense, everyone who isn't a creationist and who thinks that Darwin's theory of natural selection isn't moonshine is an adaptationist when it comes to explaining the origins of human cognition. Nevertheless, there are serious differences in research strategy between 'strong adaptationism' and 'weak adaptationism.' Strong adaptationists hold that researchers should first attempt to explain any distinctive (noncultural) complex organic design in terms of task-specific adaptations to ancestral environments (Barkow et al., 1992, Daly \& Wilson, 1995, Plotkin, 1997, Sober \& Wilson, 1998). Weak adaptationists hold that strong adaptationist arguments from design often involve Panglossian 'just-so' stories that are consistent with natural selection, but which lack evidentiary standards that could rule out indefinitely many alternative and even contrary explanations (Gould \& Lewontin, 1979, Fodor, 2001). Weak adaptationism is driven by traditional scientific assumptions of parsimony, attempting to deduce and cover the widest range of facts from the minimal set of axioms and hypotheses (Chomsky, 2001, Hauser et al., 2002). Each camp routinely claims that the other camp doesn't really understand Darwin or evolution; both routinely pay homage to George Williams' (1966) modest use of adaptationism.

For many evolutionary psychologists who take a strong adaptationist position, any functional cognitive design that is too complex to result from pure chance must be either an adaptation or a byproduct of an adaptation (Buss et al. 1998, Andrews et al., 2003). Thus, "Given any sensible analysis of the probabilities involved, a system with so many complexly interdependent subcomponents that together interact to produce complex functional output cannot be explained as anything other than an adaptation, constructed by the process of natural selection" (Tooby \& Cosmides 1990:761). This is supposed to be clear for human syntax, particularly in regard to the apparently universal and unique structure of linearized sounds that are used to convey and combine meanings (Pinker, 1997).

Moreover, "each Darwinian adaptation contains in its functional design the data of the cause - the selective force - that created it. These data are both necessary and sufficient to demonstrate scientifically the historical environmental problem that was causal in creating the adaptation" (Thornhill 1997:5). For example, the pancultural phenomenon of religious community is characterized by costly commitments and sacrifices for the sake of non-kin. This descriptive character of religion supposedly reveals the 
evolutionary explanation (problem and cause) of the phenomenon. One account goes something like this. For whatever reason, hominid social groups began to grow in size and soon a spiral of 'runaway social competition' set in that favored the formation of larger and larger groups cooperating to compete.

Because biologically-motivated 'kin altruism' decreases geometrically as a function of genetic distance, a different sort of mechanism was required to bind together ever larger groups of mostly nonkin-related individuals. Religion supposedly fits the bill (Alexander, 1987).

Weak adaptationists consider that most higher-order human cognitions are by-products of earlier evolutionary by-products that were not adapted to fulfill a specific function relative to some particular ancestral environment. These by-products originated as functionless spandrels that have been subsequently modified under cultural selection rather than natural selection. Biologically functionless, or nearly functionless, spandrels supposedly include: religion, writing, art, science, commerce, war and play. These evolutionary by-products are cultural "mountains" to the biologically "adaptive molehill" (Gould 1991:58-59). On this account, evolutionary psychology would have little to reveal about the emergence and structure of such culturally-elaborated spandrels. Because "The number and complexity of these spandrels should increase with the intricacy of the organism under consideration," the complexity, variety and importance of useable and significant spandrels will have little, if anything, to do with evolved functional design (Gould 1997:10754-10755; cf. Fodor 1998). As a matter of methodological principle, weak adaptationism is equally open to the possibility of explanations that do not directly rely on natural selection. Resort to task-and-environment-specific adaptationist accounts of the origins of human cognitive systems, including language, should be used only when comparative (fossil or ethological) evidence strongly warrants it - which is rarely the case (Gould \& Vrba, 1982, Chomsky, 2000, Finlay et al., 2001, Fodor, 2001, Hauser et al., 2003).

It is difficult to decide whether and when strong versus weak adaptationists differ in theory and ontological assumption, or differ 'only' in methodological principle and practice. Although strong adaptationists sometimes argue as if adaptedness to a particular environment or 'niche' is key to understanding complex design, their primary concern is how complex design evolved to fulfill a specific 
function. The distinction is important. Consider the bullet shapes of fish. One plausible evolutionary account is this. Given initial random variations in fish shape, laws of fluid flow would cause those who were initially more bullet-like to swim faster and more efficiently. As a result, those individuals would likely have more descendents, and in time bullet shapes would become fixed in the population. If so, we may conclude that bullet shapes fulfill the function of enabling efficient motion in water. Notice that such explanation does not appeal to anything like a 'niche' (unless water counts as a niche). Nevertheless, strong adaptationists seldom consider explanations of complexity in terms of general adaptive pressures (e.g., hydrodynamical structures in the earth's gravitational field), which have more to do with all-purpose laws of physics and broad-ranging physical conditions on the planet than with specific adaptive problems that arise from trying to keep up with changing biotic environments. In contrast, weak adaptationists often look first to these more general sorts of physical pressures and conditions in order to understand organic (including cognitive) structures (Turing, 1952, Chomsky, 2001, Leiber, 2002).

It is also often unclear whether strong adaptationism is rooted in an ontological assumption that functional specialization underlies complexity - and that complexity is sufficient for inferring function or whether evidence of complexity is primarily a "motivation" for research into function. Weak adaptationists can point to many examples of complexity - from the fractal structure of a sea cost to, crystals, snowflakes and pentamerous forms among a host of biologically unrelated organisms - for which no function is readily (or even remotely) inferable. Weak adaptationists do not see evidence of complexity and constancy as a demonstration - or even as a sufficient reason to suspect and look for some historical configuration of means being functionally appropriate to an end.

In what follows, I concentrate on the issue of methodological usefulness of a strong versus weak adaptationist position in attempting to gain significant insight and to make scientifically important advances and discoveries in human cognition. I argue that in cases of certain domain-specific cognitive competencies (e.g., folkbiology) strong adaptationism has proven useful but not necessary to recent progress in the field. In other cases having to do with group-level belief systems (e.g., religion) strong adaptationism has involved specious use of evolutionary thinking to press tendentious views of morality. 
In still other cases (e.g., language) a weak adaptationist strategy has been arguably most productive in advancing scientific understanding, without precluding that the structures uncovered by other means are actually adaptations.

As we shall see, strong adaptationism appears to do best when there is evidence of well-structured phylogenetic homology. In cases of certain domain-specific cognitive competencies (e.g., folkbiology, folkspychology), there is such evidence of well-structuring and homology. In other cases having to do with group-level belief systems (e.g., religion, culture), there is no well-definable "structure" per se and thus no relevant homology even to look for (although there are various aspects of religious belief and practice that that do have homologies, including folkbiology). In still other cases (e.g., human syntax, counterfactual reasoning), there is obvious well-structuring but no apparent homology.

2. Strong Adaptationism: The Case For Folkbiology. To get along in the world, people need to be able to understand and predict the general properties and behaviors of physical objects and substances (physics), the more specific properties of plants and animals (biology), and the particular properties of their fellow human beings (psychology). Recent developmental, cognitive and cross-cultural experiments strongly indicate that all (non-brain-damaged) humans have distinct core faculties of mind with privileged access to these distinct but overlapping domains of nature: folkmechanics (object boundaries and movements), folkbiology (biological species configurations and relationships), folkpsychology (interactive agents and goal-directed behavior) (for reviews, Hirschfeld \& Gelman, 1994, Sperber et al., 1995, Pinker, 1997, Geary \& Huffman, 2002). These plausibly innate (but maturing), domain-specific faculties are candidates for naturally-selected adaptations to relevant and recurrent aspects of ancestral environments. Under analytic idealization they are 'universal' and 'autonomous' from other cognitive faculties the way the visual system is universal and autonomous from other cognitive and biological systems (with significant individual genetic variation, and viability only in functional interaction with others faculties) (Medin \& Atran, in press).

Take the case of folkbiology. Humans and their ancestors undoubtedly depended for their survival on intimate interaction with plants and animals, which likely required anticipatory knowledge of 
at least some plant and animal species (it doesn't really matter which individual apple you can eat, or whether its Leo or Larry the tiger who can eat you). This makes it likely (but not necessary) that adaptations for special dealings with plants and animals evolved. In addition, there is growing and converging evidence for innateness and domain-specificity in human folkbiological understanding. Although domain-specificity is a weaker claim than adaptation (and innateness is a weaker claim than domain-specificity), evidence for domain-specificity helps to focus claims and research on adaptations.

Evidence for domain-specificity in folkbiology comes from a variety of converging sources (Atran, 2001a). These include: ethology (comparative studies of species recognition), cross-cultural studies (universality of special taxonomic design), developmental psychology (precocity and regularity in acquisition of essentialized species concepts and ranked taxonomic groupings), cognitive psychology (independence from perceptual experience of biological essentialism and taxonomic organization), pathology (selective cerebral impairment of folkbiological taxonomies and distinct taxonomic levels), social and educational studies (hyperactive use of biological essentialism and taxonomization, and their resistance to inhibition through formal or informal instruction or changing social conditions), and cognitive anthropology (rapid cultural transmission, easy mnemonic retention, and enduring historical survival of any given folkbiological taxonomy under varied and changing conditions of experience). No single condition may be necessary for domain-specificity; however, joint satisfaction of these conditions constitutes strong evidence for it (although they provide no causal explanation of it).

Phylogenetic comparisons of humans with other primates show some evidence for homology, and thus provide a good base from which to speculate about adaptation. For example, some nonhuman species can clearly distinguish several different animal or plant species (Cerella, 1979, Lorenz, 1966, Herrnstein, 1984). Vervet monkeys even have distinct alarm calls for different predator species or groups of species: snake, leopard and cheetah, hawk eagle, and so forth (Hauser, 2000). Chimpanzees may even have rudimentary hierarchical groupings of biological groups within groups (Brown \& Boysen, 2000).

Only humans, however, appear to have a concept of (folk) species as such, as well as taxonomic rankings of relations between species. The human taxonomic system for organizing species appears to be 
found in all cultures (Berlin et al., 1973, Atran, 1990, Berlin, 1992). It entails the conceptual realization that, say, apple trees and turkeys belong to the same fundamental level of (folk)biological reality, and that his level of reality differs from the subordinate level that includes winesap apple trees and wild turkeys as well as from the superordinate level that includes trees and birds. This taxonomic framework also supports indefinitely many systematic and graded inferences with respect to the distribution of known or unknown properties among species (Atran, 1998). The pigeonholing of species into a hierarchy of mutually exclusive taxa arguably allows the incorporation of indefinitely many species and biological properties into an inductively coherent system that can be extended to any habitat whatsoever, thus facilitating adaptation to any habitat (a hallmark of $\underline{\text { Homo sapiens) }}$.

In every human society, people seem to think about plants and animals in the same special ways. These special ways of thinking, which can be described as 'folkbiology,' are basically different from the ways humans ordinarily think about other things in the world, such as stones, tools or even people:

From the most remote period in the history of the world organic beings have been found to resemble each other in descending degrees, so that they can be classed into groups under groups.

This classification is not arbitrary like the grouping of stars in constellations. (Darwin,1859:431). The structure of these hierarchically-organized groups, such as white oak/oak/tree or mountain

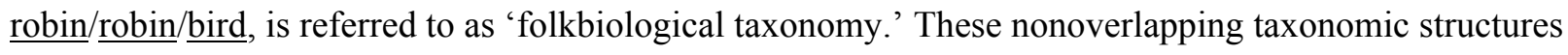
can often be interpreted in terms of speciation (related species descended from a common ancestor by splitting off from a lineage).

Folkbiological ranks vary little across cultures as a function of theories or belief systems. Ranks are intended to represent fundamentally different levels of phenomenal (readily perceived) reality, not convenience (Berlin, 1992). In principle, this ranking system allows incorporation of indefinitely many folk species into an inductive compendium that 'automatically' connects properties of the new species to the properties of all other species. This taxonomic framework supports indefinitely many systematic and graded inferences about the distribution of known or unknown properties among species (Atran, 1998). 
People in all cultures studied on the issue partition local biodiversity into taxonomies that are structurally anchored to the level of the 'generic species' (Berlin et al., 1973, Atran, 1990), the common man's (folk) species (Wallace 1889:1). Generic species often correspond to scientific species (e.g., dog, apple tree); however, for a majority of perceptually salient organisms, such as vertebrates and flowering plants, a scientific genus frequently has only one locally occurring species (e.g., bear, oak). There is growing experimental and cross-cultural evidence of a commonsense assumption that each generic species is presumed to have underlying causal nature, or essence, which is uniquely responsible for the typical appearance, behavior and ecological preferences of the kind (Gelman \& Wellman, 1991, Hickling \& Gelman, 1995, Atran et al., 2001, Sousa et al., 2002).

People in diverse cultures consider this essence responsible for the organism's identity as a complex entity governed by dynamic internal processes that are lawful even when hidden. This essence maintains the organism's integrity even as it causes the organism to grow, change form and reproduce. For example, a tadpole and frog are conceptualized as the same animal although they look and behave very differently, and live in different places. Western philosophers, such as Aristotle and Locke, attempted to translate this commonsense notion of essence into some sort of metaphysical reality, but evolutionary thinkers reject the notion of essence as such (Hull, 1965, Mayr, 1982). Nevertheless, biologists have traditionally interpreted this conservation of identity under change as due to the fact that organisms have genotypes separate from phenotypes.

Although biological science does not abide metaphysical essentialism, there is a wide variety of evidence supporting the notion of psychological essentialism (Ahn et al., 2001); that is, even when people do not have specific ideas about essences they may nonetheless have a commitment to the idea that there is an underlying nature (i.e., they may have an 'essence placeholder,' Medin and Ortony, 1989). This hidden, causal essence is presumably responsible for the manifest properties of the kind. The special causal presumptions inherent in essentialism cannot apparently be derived from more domain-general notions of causality (e.g., a three-legged tiger is still presumed to be a quadruped by nature but a threelegged or bean-bag chair is not although most chairs are quadrupedal, Atran, 1987a). The fact that 
biological science can overturn psychological essentialism in theory construction doesn't imply that psychological essentialism is dismissible from everyday thought, any more than rejection of constant intervals of space and time in physics implies abandoning ordinary use of space and time (Atran, 1990).

Briefly, then, there is a folkbiological system (FBS) of the human mind. It discriminates and categorizes parts of the flux of human experience as 'biological,' and develops complex abilities to infer and interpret this highly structured domain. In a general sense, there is nothing intrinsically different about FBS - in terms of innateness, evolution or universality - than the visual system (VS) or any other evolved cognitive system. FBS is no more (or less) 'autonomous' from the surrounding social environment, or from other mental systems, than VS is detachable from surrounding light and object patterning or from other physical systems (including linguistic and other cognitive systems, Marr, 1982).

FBS and VS do not exist, and cannot develop, in isolation, but only as subsystems of even more intricate structures. Moreover, to function properly, such systems require adequate access and exposure to the appropriate environmental input that triggers or enables them; otherwise they tend to degenerate (Hubel, 1988). Thus, claims about the biological 'autonomy' or 'modularity' of FBS or VS refer only to a specifiable level of systemic functioning, within a system hierarchy, under appropriate environmental conditions. Claims for 'innateness' refer only to special biological preparedness that canalizes maturing and developing manifestations of FBS under environmental constraints. This does not imply genetic uniformity among individuals. A difficult empirical issue concerns the extent to which other cognitive systems, such as folkpsychology and folkmechanics, are themselves geared to interface with folkbiology.

FBS constrains and guides the way biological inferences are generalized from particular instances (experiences, observations, exemplars). The particular persons observed, actual exemplars targeted, and specific inferences made can vary a lot from person to person. Nevertheless, much as rain falling anywhere in a mountain valley converges into the same natural mountain-valley river basin (Waddington, 1959), so each person's knowledge will converge (in the appropriate cultural idiom) toward the same basin of thought and action (Sperber, 1996). 
Thus, many different people, observing many different exemplars of dog under varying conditions of exposure to those exemplars, all still generate more or less the same general concept of dog. The concept dog - or any other basic sort of living-kind concept - represents more than just 'correlational features in the world.' It is hard to imagine how a categorization system exclusively attuned to perceptually-based 'correlational structure' (cf. Rosch et al., 1976, Berlin, 1992) could possibly predict the classification of Pekinese with Saint Bernards and not Persian cats, and huskies with chihauhuas and not wolves - much less the convergence across cultures of people's understanding that tadpoles belong with frogs, caterpillars with butterflies, and so forth. Rather, correlated surface features together with deep inferential principles that go beyond given appearances (e.g., essentialism) spontaneously create natural living-kind categories that capture and predict organic relationships at roughly the level of human ecological proclivity (including larger vertebrates and flowering plants) (Atran, 1987b).

Within the emerging paradigm of cognitive domain-specificity, there is much speculation and controversy, as might be expected in any young and dynamic science. For example, there are competing accounts of how human beings acquire basic knowledge of the everyday biological world, including the categorical limits of the biological domain and the causal nature of its fundamental constituents. One influential view of conceptual development in folkbiology has been articulated by Susan Carey and her collaborators (Carey, 1985, Carey \& Spelke, 1994, Solomon et al., 1997). On this view, young children's understanding of living things is embedded in a folkpsychological, rather than folkbiological, explanatory framework. Only by age 7 do children begin to elaborate a specifically biological framework of the living world, and only by age 10 does an autonomous theory of biological causality emerge that is not based on children's understanding of how humans think and behave. A competing view is that folkbiology and folkpsychology emerge early in childhood as largely independent domains of cognition that are clearly evident by ages 4 or 5, and which may be innately differentiated (Atran, 1987, Gelman \& Wellman, 1991, Keil, 1994, Hatano \& Inagaki, 1999).

To address this issue, a series of cross-cultural experiments were carried out (Atran et al., 2001, Sousa et al., 2002, Ross et al., 2003). One set of experiments shows that by the age of 4-5 years (the 
earliest age tested in this regard) urban American, rural Yukatek Maya, and urban and rural Brazilian children employ a concept of innate species potential, or underlying essence, as an inferential framework for understanding the affiliation of an organism to a biological species, and for projecting known and unknown biological properties to organisms in the face of uncertainty (Atran et al., 2001, Sousa et al., in press). For example, young children overwhelmingly believe like adults that the identity of animals and plants follows that of their progenitors, regardless of the environment in which the progeny matures (e.g., progeny of cows raised with pigs, acorns planted with apple seeds, cf. Gelman \& Wellman, 1991).

Another set of experiments shows that whereas young urban American children exhibit strong anthropocentric construals of nonhuman biological kinds, the youngest Maya children, as well as Native American (Menominee) and rural majority-culture American children, do not (Atran et al., 2001, Ross et al., in press). These children do not initially need to reason about nonhuman living kinds by analogy to human kinds. The fact that urban American children show anthropocentric bias appears to owe more to a difference in cultural exposure to nonhuman biological kinds than to a basic causal understanding of folkbiology per se (cf. Inagaki, 1990). Together, the first two sets of experiments suggest that folkpsychology can't be the initial source of folkbiology.

A third set of experiments reveals significant cross-cultural agreement in folktaxonomic structures, and in correspondence of folktaxonomies with evolutionary taxonomy (Lopez et al., 1997, Atran, 1999, Bailenson et al., 2002). A final set of results shows the same taxonomic rank being cognitively preferred for biological induction in two diverse populations: people raised in the Midwestern USA and Itza' Maya of the Lowland Mesoamerican rainforest (Atran et al., 1997, Coley et al., 1997). This is the generic species - the level of oak and robin. These findings cannot be explained by domaingeneral models of similarity because such models cannot account for why both cultures prefer specieslike groups in making inferences about the biological world, although Americans have relatively little actual knowledge or experience at this level. In fact, general relations of perceptual similarity and expectations derived from experience produce a 'basic level' of recognition and recall for many Americans that corresponds to the superordinate life-form level of folkbiological taxonomy - the level of 
$\underline{\text { tree }}$ and bird (Rosch et al., 1976). Still, Americans prefer generic species for making inductions about the distribution of biological properties among organisms, and for predicting the nature of the biological world in the face of uncertainty. Together, these findings suggest the generic-species level to be a partitioning of the universal (folk)ontological domains of plant and animal into mutually exclusive essences that are assumed (but not initially known) to have unique underlying causal natures. [By '(folk)ontological' is meant the apparent structure of the world that panhuman cognitive structures especially domain-specific ones - intuitively (and to some extent, innately) present us with.]The findings intimate that folkbiology represents evolutionary design; that is, universal taxonomic structures, centered on essence-based generic species, are routine 'habits of mind,' which may be in part naturally selected to grasp relevant and recurrent 'habits of the world.'

In the case of folkbiology, adaptationism may justifiably serve as a heuristic that guides research; however, it has no descriptive or explanatory role. Domain-specificity is as far as the scientific account goes (for now). A strong adaptationist stance also helps to counter claims that folkbiology develops ontogenetically as an 'exapted learning mechanism' (Andrews et al., 2003). [« Exaptation» (Gould \& Vrba, 1982) is a modern rendition of Darwin's concept of « pre-adaptation ». It is a pre-existing trait that has already evolved (e.g., feathers for insulation) but which acquires a new functional effect (feathers for flight) without being naturally-selected for this effect.] For example, in the controversy over whether folkbiology develops out of folkpsychology, or constitutes a functionally autonomous and pre-existing mode of construing the world, initial arguments focused on the fact that the structural representation of (essentialized taxonomy) in the adult state is more or less uniform across individuals and cultures. If so, it is unlikely that widely varying learning conditions are responsible for such a relatively stable and uniform state; however, evidence for developmental specificity was lacking.

The recent studies cited suggest that the apparent effects of folkpsychology on developing folkbiology (e.g., anthropocentric interpretations of animals and plants) weaken or disappear for 'nonstandard' populations, that is, for any human group other than children or students linked to major research universities. One interpretation is that nonstandard societies more closely approximate ancestral 
conditions of intimate interaction with nature. By contrast, standard populations (the near-exclusive focus of most developmental and cognitive psychology) need compensatory learning strategies for lack of sufficient exposure to triggering conditions that enable folkbiological knowledge, including strategies derived from folkpsychology and even folkmechanics (Au \& Romo, 1999).

From this vantage, the study of 'standard' populations reveals more about the effects of devolutionary cultural processes on innate knowledge than about the character of innate knowledge as such - much like the study of language acquisition in feral children tells us more about how the language faculty degenerates than about how it evolved to develop (Medin \& Atran, in press). Notice, though, that the evidence cited against exaptation stems from cross-cultural research. This research may be compatible with heuristic use of prior or post hoc adaptationist interpretation, but by no means requires it for description or explanation. Other aspects of folkbiology might benefit from a weak adaptationist strategy that looks at general physical and processing constraints (e.g., economy of information through taxonomic organization), as may important aspects of folkmechanics and even folkpsychology (e.g., embedding of mental states, see below).

3. Spurious Adaptationism: The Case Against Religion. According to Andrews and company (2003), adaptationism is not an ontological commitment; rather, they endorse the view of Sober and D. S. Wilson (1998) that it is an epistemological stance that guides research into discovering whether or not phenotypic traits are actually adapted to their environment. As indicated above, this stance is perfectly acceptable, and sometimes productive, as a research heuristic. It is not acceptable as a requirement for research. The work of Sober and D. S. Wilson (especially of D.S. Wilson, 2002), on social traits as (group-selected) adaptations for a group-level morality that is fundamentally selfish between groups but unselfish within groups provides a cautionary example about the abuse of adaptationism.

Sober and Wilson's argument rests on some characteristics of groups being group-level adaptations in much the same way that some features of single phenotypes are individual-level adaptations. Just as an individual can be considered a complex "vehicle" (Dawkins, 1976) or "interactor" (Hull, 1988) for the vertical genetic transmission and propagation of phenotypically-realized traits across 
generations of kin-related individuals, so the group can be considered a vehicle or interactor for the horizontal (or vertical) transmission of cultural (or biological) traits within and across nonkin- (or kin-) related populations over time. Take religious sacrifice, which generally runs counter to calculations of immediate utility, such that future promises are not discounted in favor of present rewards. In some cases, sacrifice is extreme. Although such cases tend to be rare, they are often held by society as religiously ideal: for example, sacrificing one's own life or nearest kin. Researchers sometimes take such cases as prima facie evidence of "true" (nonkin) social altruism (Rappaport 1999, Kuper 1996), or group selection, wherein individual fitness decreases so that overall group fitness can increase (relative to the overall fitness of other, competing groups) But this may be an illusion.

A telling example is contemporary suicide terrorism (Atran 2003a). Consider the "Oath to Jihad" taken by recruits to Harkat al-Ansar, a Pakistani-based ally of Al-Qaida., which affirms that by their sacrifice they would help secure the future of their "family" of fictive kin: "Each [martyr] has a special place - among them are brothers, just as there are sons and those even more dear." In the case of religiously-inspired suicide terrorism, these sentiments are purposely manipulated by organizational leaders, recruiters and trainers to the advantage of the manipulating elites rather than the individual (much as the fast food or soft drink industries manipulate innate desires for naturally scarce commodities like fatty foods and sugar to ends that reduce personal fitness but benefit the manipulating institution). No "group selection" is involved, only cognitive and emotional manipulation of some individuals by others.

There is no a priori reason (other than parsimony, perhaps) to think that group-level adaptations cannot exist. Nevertheless, there is no known instance of supposed group-level adaptations in nonhumans that cannot be formally translated into considerations of inclusive fitness applied to individuals (Reeve, 2000, Maynard-Smith, 1998, Atran 2003c). In the case of humans, recourse to group-level traits often appears motivated by attempts to scientifically deal with moral or political behaviors. Again, there is no principled reason to think this cannot, or should not, be done. The problem, though, is that the descriptive accounts of human behavior on which the analyses and explanations are based, have little or no scientific worth. Normative descriptions of human group-level phenomena, such as "religion" and "culture," 
artificially set external boundaries and define internal structural features, and greatly over systematize and regularize processes and patterns. It is not just that it may be very hard to tease apart the adaptations from transient problem-solutions and other complex entities. It is that the issue of adaptation cannot be coherently addressed at the level desired given the way that the phenomena to be explained are described.

Sober and D.S. Wilson assume that social norms are actual behavioral traits that undergo Darwinian selection, as do many sociobiologists (e.g., E.O. Wilson, 1978). In fact, purported norms are generally summary digests of lone analysts and anthropologists struggling to reduce the flux of the social experiences they observe into manageable proportions that can be reduced to a monograph or dissertation. There is almost never any information on individual variation, or specification of who is to suppose to hold these norms (Atran, 2002): Whoever the anthropologist happened to live with? An omniscient informant? Some expert(s)? Most people in the society? Without such information it is impossible to verify or falsify claims about the existence of norms, much less their evolution.

Sober and Wilson contend that a 'random sample' of anthropological reports provides evidence for norms and group-level design. Many of these reports are found in the Human Relations Area Files (HRAF) housed at Yale. The HRAF's founder, George Murdock (1949), expressly required that all entering reports be formulated as normative, functionalist and behaviorist accounts of the societies they described. These reports were specifically designed to ignore or downplay individual variation, complex interactions and cognitive structures in order to provide a functional account of human society. A random sample of a thoroughly biased sample, no matter how statistically significant, is still a biased sample.

Sober and Wilson (1998:163) defend reliance on the HRAF disingenuously:

[W] have been told that many early ethnographies (which contribute disproportionately to the HRAF) overemphasize the importance of social norms in tribal societies. Further research on the same societies often reveals more flexible and individualistic aspects of behavior.... However, it is important to avoid the assumption that knowledge always advances and that modern ethnographers are invariably more enlightened than their predecessors. 
This is a startling argument in that there is no attempt whatever to examine the theoretical objections or empirical alternatives to functionalism that have marked most advances in the field for the last half century. Even more striking, reputable biologists who seriously question whether group selection contributes anything to explaining the biology of colonies of nonhuman organisms, blithely accept Sober and Wilson's pronouncements on the functional role of social norms in the group-selection of human cultures. These are characterized as the 'most rewarding' (Maynard-Smith, 1998) and 'most valuable' (Reeve, 2000) aspects of Sober and Wilson's work, and as the primary (and perhaps only) novel contribution of group-selection theory to evolutionary theory (cf. Williams, 1992). It's as if anthropologists were to tell biologists to ignore the theories and discoveries of the last fifty years (e.g., DNA, neurotransmitters, cloning) in favor of those of a bygone era.

In these group-selection theories, functionalism, which is alive and well in biology, is confounded with functionalism in anthropology, which has been in decline for at least half a century. Functionalism in anthropology, where it is a dying metaphor, was initially derived from $19^{\text {th }}$-century biological functionalism, which has since developed into an insightful and instrumental research strategy. One immediate drawback to functionalism in the study of human societies is that takes no account of intention and other critical aspects of human cognition. In biology, disregard of intention led to a breakthrough in understanding. In anthropology and psychology, it led to the dead end of behaviorism.

Of course, it is possible that there has been no cumulative progress in anthropological understanding of human thought and behavior for half a century. One argument would be that no progress has been made in cognitive anthropology (or its close ally cognitive psychology) - an argument difficult to defend. Even acknowledging some progress wouldn't matter in the end, though, because mental structures are simply 'proximate mechanisms' to be ignored - at least at the initial stage of study - in trying to make scientific sense of culture. Although human cultures perhaps developed 'to function as adaptive units via many proximate mechanisms' (Sober \& Wilson, 1998:182), it is possible to study cultures as 'phenotypes' without describing the proximate computational machinery that generates them: 
As long as the proximate mechanisms result in heritable variation, adaptations will evolve by natural selection. There is a sense in which the proximate mechanism doesn't matter. If we select for long wings in fruit flies and get long wings; who cares about the specific developmental pathway?... if humans have evolved to coalesce into functionally organized groups, who cares how they think and feel? (Sober \& Wilson, 1998:193; cf. Dennett, 1995:359)

Even if there were functional norms, their information content and behavioral correlates would likely be too variable and fluctuating to meet minimum conditions of Darwinian selection (for examples, see Atran, 2001b, 2002). Unlike genes, ideas (information content of norms) rarely copy with anything close to absolute fidelity (Sperber, 1996). In the overwhelming majority of cases, an idea undergoes some sort of modification during communication. For example, arbitrarily select any news item and see how the different news media present it. The real mystery is how any group of people manages an effective degree of common understanding given that transformation of ideas during transmission is the rule rather than exception. If transformation (mutation or drift) affects the information at a greater rate than high-fidelity replication, then a favorable or unfavorable selection bias cannot develop for the replicated (hereditary) information (Williams, 1992:12).

Sober and Wilson reduce complex distributions of humans behaviors to artificially coherent bundles of norms, termed 'religion' or 'culture.' As such, their adaptationist accounts of religion and culture amount no more than would any adaptationist 'explanation' of magic mountains or unicorns. These pseudo-adaptationist accounts are often historically tendentious, sometimes pernicious. An example is D. S. Wilson's (2002) notion of Judaism as an ‘adaptive superorganism' whose eugenics program is designed to produce cooperative cabals of intelligent individuals able to dominate other groups through intergroup competition (cf. MacDonald, 1998). The argument is largely anecdotal and highly selective historically:

Jewish history is not as simple as a displaced people struggling to survive amidst hostile neighbors....A common pattern was for Jews to form an alliance with one gentile segment of a host nation, usually the ruling elite, to exploit another gentile segment, such as the peasantry.... 
This kind of relationship is illustrated by Joseph in the biblical account of the sojourn in Egypt. (D.S. Wilson, 2002:141-142)

Whether or not the biblical story is factual proves irrelevant because 'similar alliances with the ruling classes existed throughout Jewish history.' Although more easily verifiable and well-documented instances of immigrant Jews allying themselves with poorer, weaker segments of society is not mentioned (European anarcho-syndicalists, the U.S. National Association for the Advancement of Colored People, etc.), this too could be easily assimilated to the divide and conquer mentality of 'us/them thinking': 'Multilevel selection theory accounts for the double standard of the Hebrew Bible... No other theoretical framework fits the well-known facts of Judaism and other religions so well' (D.S. Wilson, 2002:135).

There is nothing in these authors' accounts that suggest any understanding of, or interest in, efficient or proximate causes of religious and cultural behaviors: that is, the material production of statistically identifiable distributions of individual mental representations and their public expressions (in artifacts and physical institutions) in specified ecological contexts. Aside from an unanalyzed notion of group-level belief systems, what does it mean to have 'fitness consequences' at the level of a whole culture, social system or religion? As Dan Sperber (1996) asked in an open communication to the Evolution and Human Behavior Society: Is fitness a matter of having descendants with a recognizable ideology? Of population size? Of variations in size (expansion)? Of duration? Of some weighted combination of size and duration? What of social systems that expand rapidly at the expense of heritability (empires)? Without answers to such questions (and none seem forthcoming) the idea of societal-level fitness is hopelessly vague.

It's not that thorough commitment to strong adaptationism's epistemological framework is bound to lead to such nonsense. But requiring that every manifestation of human complexity be interpreted with reference to a possible strong adaptationist scenario (as a functional adaptation or concomitant of an adaptation) encourages such abuse. Why not 'adaptations' for every frequently encountered type of copulation, killing, kin-reckoning, regularly produced counterfactual belief (e.g., supernatural agents as bodiless intelligent and emotional beings, life after death, miraculous births, etc.), or routinely 
encountered social artifact or institution (houses, masks, governments, standing in line)? Although commonsense might suppose at least some of these suggestions to be ridiculous, the putative equation of adaptationism with science often allows commonsense to be trumped. After all, isn't it science's job to transcend commonsense, as it so successfully does in physics, chemistry or molecular biology?

It's not that religious and cultural cognitions and behaviors lack interesting generalities that cannnot be productively investigated through evolutionary approaches (Atran, 2002); only, religions and cultures as selectable objects simply don't exist (except in a loose commonsense way), any more than do whole species (over and above constituent, genealogically-related individuals). There are, in fact, statistically reliable distributions of religious beliefs among populations that indicate 'cultural consensus.' For example, principal components analysis of interinformant agreement on a range of probes (e.g., how spirits affect nature) can indicate a single factor solution wherein each actor's first factor score is positive (with first factor scores thus providing a measure of 'cultural competence' for each individual with respect to consensual model, Atran et al., 2002; cf. Romney et al., 1986). The class of such distributions of religious beliefs - or 'religion' for short - involves extraordinary use of ordinary cognitive processes to passionately display costly devotion to counterintuitive worlds governed by supernatural agents. Core religious beliefs minimally violate ordinary notions about how the world is, with all of its inescapable problems, thus enabling people to imagine minimally impossible supernatural worlds that solve existential problems, including death and deception. For example, a bodiless and omnisicient God (who has simultaneous access to all states of mind and all sources of information), who can be a jealous God (with an array of emotions but no accompanying bodily states), is able to change the physical world at will (but without necessarily employing physical force or upsetting the known laws of the material universe), to accommodate a single person's prayers and wishes (to save a relative from an airplane that has already exploded in midair).

Developmental and cross-cultural experiments indicate that religious beliefs typically involve culturally-developed manipulations of innate and domain-specific cognitive constraints (much as the pornography or fast-food industries typically involve artificial manipulations of innate likings for sexual 
partners and protein-rich foods). The conceptual foundations of religion are intuitively given by taskspecific panhuman cognitive domains, including folkmechanics, folkbiology, folkpsychology. In every religion, operation of the structural principles that govern the ordinary and 'automatic' cognitive construction of these core domains are sometimes pointedly interrupted or violated, as in poetry (cf. Kelly \& Keil, 1985). In these instances, counterintuitions result that form the basis for construction of special sorts of counterfactual worlds, including the supernatural. For example, a world that includes selfpropelled, perceiving or thinking mineral substances (e.g., Maya sastun, Arab tilsam [talisman]) or beings that can pass through solid objects (angels, ghosts) (cf. Atran \& Sperber, 1991, Boyer, 1994). In these experiments people readily create and retain in memory only those supernatural agents who minimally violate our innately-given and domain-specific expectations about the (folk)ontological structure of the everyday world This leaves nearly all of the world's ordinary structure intact. For example, supernatural agents in every known society have many of the usual emotions, perceptions, beliefs, desires, linguistic competence and inferences that ordinary humankind has; only, they are also typically somewhat stronger, faster, more knowledgeable and less likely to have false beliefs (J. Barrett et al., 2001, Knight et al., in press).

As a result, religious concepts need little in the way of overt cultural representation or instruction to be learned and transmitted. A few fragmentary narrative descriptions or episodes suffice to mobilize an enormously rich network of implicit background beliefs. For instance, if God is explicitly described as being jealous and able to move mountains, He is therefore implicitly known to have other emotions, such as anger and joy, and other powers, such as the ability to see and touch mountains or to lift and sight most anything smaller than a mountain, such as a person, pot, pig or pea.

People retain in long-term memory such minimally counterintuitive agents and situations, but don’t so readily retain agents and situations that involve more numerous or more preposterous counterintuitions (e.g., an omnipotent, unmoving clump of jelly descended from talking lava) (J. Barrett \& Nyhof, 2001, Boyer \& Ramble, 2001, Atran \& Norenzayan, in press). As a result, these more absurd agents and situations are less likely to survive cultural transmission and to become enduring aspects of 
any religion. Moreover, by transcending our ordinary world just enough to master it for us, minimally counterintuitive agents can provide an easily imaginable resolution of ever present existential problems for which no intuitively coherent, logically consistent or empirically tractable solution can possibly exist, such as avoidance of death or natural catastrophe. This further contributes to willingness to have faith in, retain and transmit such beliefs, which results in their cultural survival in religious traditions. For example, in a variation of an experiment by Cahill and colleagues (1995) on the effects of adrenalin activation on memory for emotional events, Atran and Norenzayan primed American students and Yukatek Maya with one of three stories matched for event structure and differing minimally in content. When subjects were primed with stories containing a death scene (as opposed to a nonstressful mundane or religious scene), and then told about foreigners praying for barren local women to have children, the subjects expressed stronger confidence in the existence and power of supernatural agents (they also had better recall for the story containing the death scene).

This is not to say that the function of religion is to promise resolution of all outstanding existential anxieties anymore than the function of religion is to neutralize moral relativity and establish social order, to give meaning to an otherwise arbitrary existence, to explain the unobservable origins of things, and so forth. It is rather that existential anxieties and moral sentiments constitute - by virtue of evolution - ineluctable elements of the human condition; and that the cognitive invention, cultural selection and historical survival of religious beliefs owes, in part, to success in accommodating these elements. There are other factors in this success, involving naturally-selected elements of human cognition, such as the inherent susceptibility of religious beliefs to distinctive, biologically-prepared sorts of conceptual and mnemonic processing. As interacting humans 'walk' through this evolutionary landscape they everywhere tend to converge onto religious paths whose cultural trajectories conform to its contours in highly predictable ways (Atran, 2002).

From this perspective, religions emerge as a recurring by-product of the complex evolutionary landscape that sets cognitive, emotional and material conditions for ordinary human interactions. There are adaptationist arguments to be made as to what these by-products are by-products of. For example, a 
key feature of the supernatural agent concepts common to all religions is the triggering of an 'Innate Releasing Mechanism' (Tingbergen, 1951) or 'agency detector,' whose proper (naturally-selected) domain likely encompasses animate objects relevant to hominid survival - such as predators, protectors and prey - but which actually extends to moving dots on computer screens, voices in wind, faces on clouds (much as flying insects belong the proper domain of the frog's bug-catching mechanism, whereas wads of black paper dangling on a string belong to the mechanism's actual domain, cf. Sperber, 1994). In line with this speculation, it is reasonable to propose research based on the prediction that our brains are wired to spot lurkers (and to seek protectors) where conditions of uncertainty prevail (when startled, at night, in unfamiliar environments, during sudden catastrophe, in the face of solitude, illness, or prospects of death, etc.). From an evolutionary vantage, it's usually better to be safe than sorry (cf. Guthrie, 1993). Although adaptationist arguments can plausibly shed light on certain aspects of religion's emergence, there is no plausible sense in which religion as a whole (or any group-level distribution of beliefs) is a group-level adaptation, like a bee-hive. This includes martyrdom, which is more cultural manipulation of individual sentiment than natural expression of group desire (Atran, 2003a).

4. Weak Adaptationism: The Case of Language. Strong adaptationists and weak adaptationists alike accept the premise that natural selection is the only known (noncultural) explanation for functionally complex design - a functionally complex design being one that is 'workable' (Gould, 1997) or 'goaldirected' (Pinker, 1997). But this doesn’t really say much. Natural complexity in itself doesn't warrant considerations of natural selection (e.g., snowflakes, crystals, the structure of organic molecules, the fractal structure of a sea coast, etc.). A workable complex design means little more than a complex design that exists (if it weren't workable it wouldn't survive). A 'goal-directed' complex design is more of a vaguely metaphorical anthropomorphic idea than a formalizable or testable concept of biology. Pinker (1997) uses goal-directed as a fuzzy sort of 'as if' notion - as if evolution were purposely designed by an ‘intelligent designer' (Wallace 1889:138), blind watchmaker (Dawkins, 1986), ‘stupid' designer (Williams, 1992:73), tinkerer (Jacob, 1977) or whoever. All one can really say that nonrandom biological design is produced by cumulative natural selection of more or less random mutations. 
One possibility consistent with this is that much complex design has no presently known explanation (most human cognitive architecture, Fodor, 2001), and there may be some functional complexity that results largely from more general physical, chemical or biological processes governing complex systems. Such textbook adaptations as the strikingly analogous aerodynamic designs of bird and bat wings, insect wings, and windborne seeds of certain trees (e.g., mahogany) may result chiefly from general physical laws and mechanical processes. Similarly, hydrodynamic laws place general constraints on the structural design of aquatic organisms, so that they tend to be bullet-shaped. Such traits as wings or bullet-shaped bodies are adapted principally to general conditions on earth (gravity, wind, water) distinctive of no particular environment. Talk of adaptation to 'ancestral conditions' has little, if any, meaning in such cases.

To be sure, these general constraints on the 'design space' of airborne and aquatic structure and movement are components of selective forces operating in particular environments. At each stage in the evolution of these traits, natural selection likely produced encoding in the genes. Nevertheless, further research into the gradual and cumulative action of natural selection on the production of wings and bulletshaped bodies in particular historical environments and phyletic lineages seems warranted only within the framework of a general design space that is already clearly in view.

Take the case of language. Strong adaptationist scenarios for the emergence of language include stories about bee dances, bird songs, fish courtship, dog barking, simian aggression displays, ape signing, hominid tool-making, object recognition, gesturing, sensorimotor intelligence, self-awareness, food sharing, hunting, spatial mapping, cheater detection, gossiping, social planning and so forth. Most can be dismissed from serious consideration because they ignore panhuman structural ('design') features of language, such as syntactic structures. Pinker and Bloom (1990) provide the most compelling story for language learning as a strong adaptation for communicating propositional structures over a serial channel.

Pinker and Bloom's proposal has two parts: demonstrating biological preparedness (using 'poverty of stimulus' reasoning) and inferring adaptation. The first part is widely accepted by strong and weak adaptationists. Indeed, it is a virtual tautology. As Hume stressed, the ability to 'automatically' 
extend a few (or finitely many) instances of experience to an indefinitely large (virtually infinite) set of complexly related cases logically requires the prior existence of projecting structures that do the work of generalization. For those who accept human minds to be biological systems that evolved under natural selection (as both strong and weak adaptationists do) the issue is decided and decidedly uninformative.

But biological preparedness doesn’t imply ‘hence, adaptation for language learning' (as Andrews et al, 2003, suggest). The claims for syntax as an adaptation at best involve retrodictions of syntactic structures discovered through weak adaptationist reasoning and research (mostly through generative grammar). No novel predictions ensue. Reasonable people can argue over whether strong adaptationism provides novel predictions or discoveries for any higher-order cognitive process. [For example, on the socalled 'cheater detection module' as an adaptation (Cosmides, 1989, Gigerenzer \& Hug, 1992, Fiddick et al., 2000), see Sperber et al, 1995, Atran 2001c]. Many adaptationist arguments for higher-order cognition are mere consistency arguments. They lack even the power of retrodiction because they so easily accommodate conflicting and contrary adaptationist accounts. [For example, according to Sedikides and Skowronski (1997:80) the symbolic self is a 'flexible and multifaceted cognitive representation of an organism's own attributes' that 'serves adaptive functions'; supporting arguments are speculative, uninformative as to any specific computational structures, and too vague to assess their truth or falsity.]

Finally, this one seriously strong adaptationist argument for language may be nearly circular, at least in its strongest claim that language was selected to communicate subject-predicate relations. There is no example I'm aware of indicating subject-predicate structures in any creature save language-competent humans. Even that stellar bonobo, Kanzi, consistently fails to apprehend such structures; his novel 'sentences' are maximally just two concatenated arguments with no subjects, such as 'chase bite,' that humans shun (Atran \& Lois, 2001). So, this strongest of adaptationists proposal may reduce to: language was naturally selected to communicate what only language can formulate (propositions).

The proposal that language emerged as a vehicle for 'thoughts struggling to get out' isn't logically circular as it's logically possible for a mind to internally represent subject-predicate relations (or any other format for structured thought) without having means to encode and externalize them (e.g., a 
program running on a computer with no keyboard, speaker or screen). [Peter Carruthers, per. comm., 5 Nov. 2002, on why Pinker's strong adaptationist view of language isn't circular (as Atran, 2003b, suggests)]. If the claim were merely for communicating predicate-argument relations, without any argument being distinguished as the subject, there would be some independent support by analogy (although no direct empirical test or confirmation). First, theories of a variety of forms of information representation (relational databases, formal logic, computer programming languages) and information processing (human vision, conceptual memory, real-time reasoning) hypothesize manipulation of predicate-argument relations.[Steven Pinker, per. comm, 8 Nov. 2002, on why his proposal is noncircular.] Second, whatever the format, communication of information (which has evolved repeatedly in the animal and plant kingdoms) has fitness benefits when uncertainty is reduced: for example, if transaction costs for information exchange are lower than costs of individually rediscovering the information (Pinker, 1997:573).

Nevertheless, for the stronger claim that syntax is selected to communicate subject-predicate relations there may be little prospect for independent support by analogy, let alone empirical support that directly tests the argument. A syntactic subject combines a logical function (a particular thematic role, typically agent) with the pragmatic function of topic in a topic-comment structure (allowing sentences to be pragmatically linked together in discourse). According to Pinker and Bloom (1990), the grammatical subject has this character because the medium of human communication is serial and attention is finite. Because attention is finite in all animals and other forms of serial communication exist in other animals, the subject in mind must have evolved to accommodate the medium of communication, and not the other way around. But the only known case of an agent-focused thought (the logical-pragmatic subject) being structurally fit to a serial communication medium is human language. How and where the fitting process got 'kick-started' is left to the dark recesses of pure speculation. 'Bootstrapping' only fudges the issue.

One alternative, weak adaptationist approach assumes no direct natural selection (no task-specific adaptation to distinctive features of ancestral environments) for language's 'creative core,' that is, the computational faculty of syntactic recursion that allows potentially infinite production of words and well- 
formed word-combinations with relatively few and finite means (Chomsky, 2000). Putting aside the argument from design as too open-ended or nearly circular, this 'minimalist program' operates on the (huge but bold) assumption that language's creative core is a recently evolved accommodation to more general physical or biological processes - in ways analogous to the apparent optimization of information flow in a material medium through minimization of 'wire length,' as in microchip design, nematodes and human brains (Cherniak, 1995). The idea is that recursion in language may be a physically optimal sort of interface (internal accommodation) between two physically suboptimal (but perhaps genetically optimal and adapted) systems of more ancient evolutionary origins: the sensorimotor system (including phonation) and the conceptual-intentional system (including categorization, reference and reasoning).

[The minimalist program uses Occam's razor to reduce the computational component for human language, which interacts with the two "external" systems, to only those elements warranted by conceptual necessity (Epstein, Thráinsson \& Zwart, 1996). Beyond Occam, though, is the metaphysical supposition that nature itself operates on principles of bare necessity, whenever it can get away with it. Chomsky's working assumption is that we can go along way - perhaps even all of the way - in understanding the computational component of language that maps meaning onto form by attempting to reduce much of the descriptive richness and cross-linguistic variation in human syntax to the following: (1) a few invariant principles for all humanly possible syntactic systems (e.g., every sentence must have a subject), (2) a very limited number of parameter settings from which irreducible cross-linguistic variation derives (e.g., subjects are either morpho-phonologically overt as in English, I desire, or optionally covert as in Spanish, (yo) deseo), (3) legibility conditions imposed by the sensorimotor system (e.g., linearization of sounds required for pronunciation imposes linear ordering on the interface representations that encode grammatical information, which yields phrase-structural properties), and (4) legibility conditions imposed by the conceptual-intentional system (e.g., positioning of semantic items in the contour of events requires the assignment of lexical items to thematic roles, such as agent, patient, instrument and so forth). An open empirical issue is which aspects of syntactic theory should be retained 
(if any) as principles or parameters, which transferred from syntax proper to the interface with the two external systems, and which eliminated after reduction to principles, parameters or interface conditions.]

The idea of physical optimality has a distinguished tradition in natural philosophy (Galileo, Newton) and natural history (Blumenbach, A.L. Jussieu) as well as in modern cosmology (Einstein, Hawking) and in studies of biological form and development (D’Arcy Thompson, 1961[1917], Maynard Smith et al., 1985). For evolutionary biology in particular, the primary objective is to discover and predict, through strictly physical and chemical means, the set of organic forms (molecular, morphological, neuronal) that are likely to emerge from a given starting point. Only then is it worthwhile to inquire into which of those forms might be selected and how. For example, extensive sharing of genomic structure among all vertebrates, and even vertebrates and invertebrates, suggests that many of the same 'master genes' program body plan and the control mechanisms of development (Gehring, 1998). Even eyes, which were thought to have evolved analogously and independently in different phyla, may be in each case a homologous derivation from the same DNA (Pax-6). Physical law and mechanical processes appear to be responsible for much of what follows: development of each component of the eye is narrowly constrained by the laws of optics and mechanical contingencies involved in sharply projecting images of three-dimensional objects onto a planar surface of receptors.

In line with Turing's (1952) vision of biological explanation, much the same organic architecture and behavior may evolve in very different historical environments just as basically similar cognitive architectures and behaviors may be developed in very different physical media (cf. Hodges, 1983, Leiber, 2002). If so, it is plausible to try to explain significant aspects of the structure and emergence of these architectures and behaviors without considering how they have been accommodated to (selected for) particular historical environments and physical media. Indeed, further understanding of particular historical and physical accommodations (e.g., the 'Cambrian explosion' of multicellular organisms, the 'real-time' processing of information) may depend crucially on such nonteleological insights. Worthiness of this approach depends on success in providing significant and surprising predictions and discoveries. In the minimalist program, these arguably (if controversially) far exceed what its originators previously 
thought possible (for a formalization, see Chomsky, 2001). At most, strong adaptationist arguments retrodict old discoveries. This isn't to deny that adaptationist arguments may ultimately prove insightful into language structure. For example, recent studies identifying multiple genetic loci for language disorders and delays seem to belie any single mutation account for language. Moreover, at least one of these genes seems to have been a target for selection, although the gene at issue (FOXP2) concerns speech and processing of morphology rather than syntactic recursion (Enard et al., 2002). In any event, even without an eventual recourse to adaptationism, novel biological and evolutionary understanding of language (and other cognitive structures) can occur beforehand.

Weak adaptationist (not necessarily minimalist) investigation of language crucially uses aspects of the strong adaptationist program, especially the comparative approach (Hauser et al., 2003). Thus, arguments for natural selection of phonation have involved claims about the uniqueness of categorical auditory discrimination and descent of the larynx in humans. Comparative studies prove otherwise: chinchillas and other mammalian species categorically discriminate human phones; deer and several bird species drop the larynx (possibly to exaggerate size, Fitch \& Reby, 2001). Perhaps human phonation is itself a by-product of a jerry-rigged combination of other by-products and adaptations: the (originally prevertebrate) alimentary system and the respiratory system of terrestrial vertebrates interface at the larynx (which drops in humans), hence by chance enabling production of phones later 'exapted' to language. Other comparative studies show contrary evidence for prehominid antiquity in parts of the conceptualintentional system. Intriguing experiments purporting to show that subordinate chimps can take the perspective of dominant chimps (Hare et al., 2001) have yet to be replicated in different laboratories (Povinelli, 2001). In any event, chimps don't seem able to repeatedly embed states of mind: [Danny thinks that [Marc believes that [Brian knows that... Etc. Short-term memory typically limits iterated embedding of mental states to five levels (L. Barrett et al., 2002); however, as with 'center-embedding' of linguistic clauses (also usually limited to under seven levels), computational machinery allows for indefinitely many embeddings. [Noam Chomsky, per. comm., 27 Oct. 2002, referring to centerembedding experiments he performed with George Miller in the early 1960s.] 
For any apparent limit, simply embed the maximal thought or phrase into the further belief or clause: '(Do) you really think that...,' or something of the sort. By giving a person more time and external memory, more embedding is interpretable in a unique and uniform way (not predicted by associationist models, connectionist or other). Other parts of the conceptual-intentional system may be more ancient in primates, including perceptually-based reference (Gallistel, 1990), categorization (Brown \& Boysen, 2000) and reasoning (Povinelli, 2000).

5. Conclusion. The intention in this paper was to explore and evaluate the methodological usefulness of strong versus weak adaptationist positions as ways to gain insight and to make scientifically significant advances in the study of in human cognition. Although it remains unclear whether or not there are real differences in the theoretical and ontological assumptions of strong versus weak adaptationists, there is often a clear and deep methodological divide. So what works best? My answer is mixed.

In folkbiology, as with perhaps other universal and "modular" cognitive domains (e.g., folkpsychology), a strong adaptationist approach does seem to provide some genuine insight with testable consequences. Such insight has proven useful but perhaps not necessary to progress in the field. To the extent that phylogenetic homologies are apparent, a strong adaptationist approach may be warranted.

Neither the inferential structure of human folkbiological taxonomy nor the recursive representational structure of human folkpsychology have obvious homologies; however, more rudimentary and phylogenetically prior aspects of these two systems do. Accordingly, one may profitably consider which functional advantages the more recently evolved aspects of the folkbiological and folkpsychological systems might have provided relative to older aspects of these systems, given what is known about corresponding changes in hominid ecological and social environments (e.g., wider roaming range, larger group size). In the case of folkbiology, such considerations underscored the claim that folkbiology and folkpsychology are evolutionarily distinct domains of (primate) cognition; and this speculative claim, in turn, motivated experiments showing that folkbiology and folkpsychology are developmentally distinct domains of (child) cognition, 
In other domains, such as religion and perhaps other group-level phenomena that are circumscribed more by folk intuition than by science (e.g., "culture"), I see strong adaptationism too often blocking scientific advance. Here, commonsense structural descriptions with little scientific value are taken as the "evidence" from which to read off functional explanations. Strong adaptationism more easily lends itself than the weaker form to this sort reductive thinking and storytelling, because strong adaptationism more readily assumes that there is a story to be told about anything in life that seems to be complex and pervasive. This facilitates specious use of evolutionary thinking to press tendentious views of group practices and beliefs that prey upon popular notions of group behavior and morality.

For language, stong adaptationism does not appear to have produced any new understanding, despite more intense effort by strong adaptationists in this domain than perhaps in any other. Here, a weak adaptationist strategy has arguably proved most productive in advancing scientific understanding, without precluding that the structures uncovered by other means are actually adaptations. In a sense, weak adaptationism is more scientifically demanding than strong adaptationism. Weak adaptationism's methodological stance follows from the belief that evidentiary standards for deciding between competing lines of research must go beyond mere consistency (which does not disallow contrary explanations), or even retrodiction, to include surprising deductions and significant empirical confirmations.

Now, I have argued as if insight and awareness, on the one hand, and prediction and discovery, on the other, are the same things when judging the relative scientific merit of one methodological stance versus another. But someone could think that the language faculty is an adaptation (claiming that this hypothesis is better warranted than any alternative on the market) and thereby gain some insight and awareness into how things fit together, without believing that an evolutionary explanation of language is likely to lead to new predictions and discoveries in linguistics.

In the end, a good way to obtain knowledge about a domain of human cognition may involve approaching a problem from both ends, initially keeping apart strong and weak strategies, then combining their respective appreciations to generate new knowledge. Viewing progress in understanding the emergence of human cognition exclusively through a lens of strong adaptationism (search first and always 
for the adaptation that a complex trait might represent) or weak adaptationism (if in doubt about some adaptation as a trait's explanation - which is usually the case - give nonadaptationist accounts the benefit) could lead science into blind alleys. To conclude that attempting a modest use and mix of strong and weak adaptationist approaches could prove most effective in producing knowledge about human cognition may appear obvious, even lame. But why, then, do so few attempt it? 


\section{$\underline{\text { References. }}$}

Ahn, W. Kalish, C., Gelman, S., Medin, D., Luhmann, C., Atran, S., Coley, J. \& Shafto, P. 2001: Why essences are essential in the psychology of concepts. Cognition, 82, 59-69.

Alexander, R. 1987: The biology of moral systems. New York: Aldine de Gruyter.

Andrews, P., Gangestad, D. \& Mathews, D. 2003: Adaptationism - How to carry out an exaptationist program. Behavioral and Brain Sciences, 25, 489-504.

Atran, S. 1987: Ordinary constraints on the semantics of living kinds: A commonsense alternative to recent treatments of natural-object terms. Mind and Language, 2, 27-63.

Atran, S. 1990: Cognitive foundations of natural history. Cambridge, UK: Cambridge University Press.

Atran, S. 1998: Folkbiology and the anthropology of science: Cognitive universals and cultural particulars. Behavioral and Brain Sciences, 21, 547-609.

Atran,S. 1999: Itzaj Maya folkbiological taxonomy. In D. Medin \& S. Atran (eds.), Folkbiology pp. 119204. Cambridge, MA: MIT Press.

Atran, S. 2001a: The case for modularity: Sin or Salvation? Evolution and Cognition, 7, 46-55.

Atran, S. 2001b: The trouble with memes: Inference versus imitation in cultural creation. Human Nature, 12,351-381.

Atran, S. 2001c: A cheater detection module? Dubious interpretations of the Wason Selection Task and logic. Evolution and Cognition, 7,183-193.

Atran, S. 2002: In gods we trust: The evolutionary landscape of religion. New York: Oxford University Press.

Atran, S. 2003a: Genesis of suicide terrorism. Science, 299, 1534-1539.

Atran, S. 2003b: Modest Adaptationism (reply to Andrews et al.). Behavioral and Brain Sciences, 25, 504-506.

Atran, S. 2003c: Théorie cognitive de la culture (une alternative évolutionniste à la sociobiologie et à la selection collective). L'Homme, 166: 107-144. 
Atran, S., Estin, P., Coley, J. \& Medin, D. 1997: Generic species and basic levels: Essence and appearance in folk biology. Journal of Ethnobiology, 17, 22-45.

Atran, S. \& Lois, X. 2001: Reply to Shanker. Current Anthropology, 42, 498-500.

Atran, S., Medin, D., Ross, N., Lynch, E., Vapnarsky, V., Ucan Ek', E., Coley, J., Timura, C. \& Baran, M. 2002. Folkecology, cultural epidemiology, and the spirit of the commons: A garden experiment in the Maya Lowlands, 1991-2001. Current Anthropology, 43, 421-450.

Atran, S., Medin, D., Lynch, E., Vapnarsky, V., Ucan Ek', E. \& Sousa, P. 2001. Folkbiology doesn't come from folkpsychology: Evidence from Yukatek Maya in cross-cultural perspective. Journal of Cognition and Culture, 1, 3-42.

Atran, S. \& Norenzayan, A. in press: Religion's evolutionary landscape: Counterintuition, commitment, compassion, communion. Behavioral and Brain Sciences.

Atran, S. \& Sperber, D. 1991: Learning without teaching: Its place in culture. In L. TolchinskyLandsmann (Ed.), Culture, schooling and psychological development. Norwood NJ: Ablex.

Au, T. \& Romo, L. 1999: Mechanical causality in children's « folkbiology. » In D. Medin \& S. Atran (Eds.), Folkbiology, pp. 355-402. Cambridge, MA: MIT Press.

Barkow, J., Cosmides, L. \& Tooby, J., Eds. 1992: The adapted mind. New York: Oxford University Press.

Barrett, J. \& Nyhof, M. 2001: Spreading nonnatural concepts. Journal of Cognition and Culture, 1, 69100.

Barrett, J., Richert, R. \& Driesenga, A. 2001: God's beliefs versus mother's: The Development of nonhuman agent concepts. Child Development, 72, 50-65.

Bailenson, J., Shum, M., Atran, S., Medin, D. \& Coley, J. 2002. A Bird's Eye View: Biological Categorization and Reasoning Within and Across Cultures. Cognition, 84, 1-53.

Barrett, L., Dunbar, R. \& Lycett, J. 2002: Human evolutionary psychology. Princeton: Princeton University Press.

Berlin, B. 1992: Ethnobiological classification. Princeton: Princeton University Press. 
Berlin, B., Breedlove, D., \& Raven, P. 1973: General principles of classification and nomenclature in folk biology. American Anthropologist, 74, 214-242.

Boyer, P. 1994: The naturalness of religious ideas. Berkeley: University of California Press.

Boyer, P., \& Ramble, C. 2001: Cognitive templates for religious concepts. Cognitive Science, 25, 535564.

Brown, D. \& Boysen, S. 2000: Spontaneous discrimination of natural stimuli by chimpanzees. Journal of Comparative Psychology, 114, 392-400.

Buss, D., Shackelford, T., Bleske, A. \& Wakefield, J. 1998: Adaptations, exaptation, and spandrels. American Psychologist, 53, 533-548.

Cahill, L., Prins, B., Weber, M. \& McGaugh, J. 1994: Beta-adrenergic activation and memory for emotional events. Nature, 371, 702-704.

Carey S. 1985. Conceptual Change in Childhood. Cambridge, MA: MIT Press.

Carey, S. 1995. On the origin of causal understanding. In D. Sperber, D. Premack \& A. Premack (Eds.), Causal cognition, pp. 268-302. Oxford: Clarendon Press.

Carey, S. \& Spelke, E. 1994: Domain-specific knowledge and conceptual change. In L. Hirschfeld \& S. Gelman (Eds.) Mapping the mind pp. 169-200. New York: Cambridge University Press.

Cerella, J. 1979: Visual classes and natural categories in the pigeon. Journal of Experimental Psychology Human Perception and Performance, 5, 68-77.

Cherniak, C. 1995: Neural component placement. Trends in neuroscience, 18, 522-527.

Chomsky, N. 2000: Minimalist inquiries. In R. Martin, D. Michaels \& J. Uriagereka (Eds.)_Step by step pp. 89-155. Cambridge, MA: MIT Press.

Chomsky, N. 2001: Beyond explanatory adequacy. MIT Occasional Papers in Linguistics, No. 20.

Cosmides, L. 1989: The logic of social exchange: Has natural selection shaped how humans reason?

Studies with Wason Selection Task. Cognition, 31, 187-276.

Cosmides, L. \& Tooby, J. 1995: Beyond intuition and instinct blindness: Toward and evolutionarily rigorous cognitive science. Cognition, 50, 41-77. 
Daly, M. \& Wilson, M. 1995: Evolutionary psychology: Adaptationist, selectionist and comparative. Psychological Inquiry, 6, 34-38.

Darwin, C. 1859: On the origins of species by means of natural selection. London: Murray.

Dawkins, R, 1976: The selfish gene. New York: Oxford University Press.

Dawkins, R. 1986: The blind watchmaker. London: Penguin.

Dennett, D. 1995: Darwin's dangerous idea. New York: Simon and Schuster.

Enard, W., Przeworski, M., Fisher, S., Lai, C., Wiebe, V., Kitano, T., Monaco, A. \& Pääbo, S. 2002:

Molecular evolution of FOXP2, a gene involved in speech and language. Nature, 418, 869-872.

Epstein, S.D., Thráinsson, H. \& Jan-Wouter Zwart, C. 1996: Introduction. In Abraham, W., Epstein, S.D., Thráinsson, H. \& Jan-Wouter Zwart, C. (eds.), Minimal ideas, pp. 1-66. Amsterdam: John Benjamins.

Fiddick, L., Cosmides, L. \& Tooby, J. 2000: No interpretation without representation: The role of domain-specific representations and inferences in the Wason Selection Task. Cognition, 75, 1-79.

Finlay, B., Darlington, R. \& Nicastro, N. 2001: Developmental structure in brain evolution. Behavioral and Brain Sciences, 24, 263-308.

Fitch, W.T. \& Reby, D. 2001: The descended larynx is not uniquely human. Proceedings of the Royal Society, Biological Sciences, 268, 1669-1675.

Fodor, J. 2001: Review of Evolution of the human mind. British Journal for the Philosophy of Science, $52,623-628$.

Frank, R. 1988: Passions within reason. New York: Norton.

Gallistel, C. R. 1990 The organization of learning. Cambridge, MA: MIT Press.

Geary, D. \& Huffman, K. 2002: Brain and Cognitive Evolution: Forms of Modularity and Functions of Mind. Psychological Bulletin, 128, 667-698.

Gehring, W. 1998: Master control genes in developmental evolution. New Haven: Yale University Press.

Gelman, S. \& Wellman, H. 1991: Insides and essences. Cognition, 38, 213-244.

Gould, S. 1997: Evolutionary psychology: An exchange. New York Review of Books, 44, 56-58. 
Gould, S. \& Lewontin, R. 1979: The spandrels of San Marco: A critique of the adaptationist programme. Proceedings of the Royal Society of London, B 205, 581-598.

Gould, S. \& Vrba, E. 1982: Exaptation - a missing term in the science of form. Paleobiology, 8, 4-15. Guthrie, S. 1993: Faces in the clouds: A new theory of religion. New York: Oxford University Press. Hare, B., Call, J., \& Tomasello, M. 2001: Do chimpanzees know what conspecifics know? Animal Behaviour, 6,139-151.

Hatano, G. \& Inagaki, K. 1999. A developmental perspective on informal biology. In D. Medin \& S. Atran (Eds.), Folk biology pp. 321-354. Cambridge MA: MIT Press.

Hauser, M. 2000: What animals really think. New York: Henry Holt \& Company.

Hauser, M., Chomsky, N. \& Fitch, W. T. 2002: The faculty of language. Science, 298, 1569-1579.

Herrnstein, R. 1984: Objects, categories, and discriminative stimuli. In H. Roitblat (Ed.), Animal cognition. Hillsdale, NJ: Erlbaum.

Hickling, A. \& Gelman, S. 1995: How does your garden grow? Evidence of an early conception of plants as biological kinds. Child Development, 66, 856-876.

Hirschfeld \& Gelman, S., Eds. 1994: Mapping the mind: Domain-specificity in cognition and culture. New York: Cambridge University Press

Hodges, A. 1983: Alan Turing: The enigma. New York: Simon and Schuster.

Hubel, D. 1988: Eye, brain, and vision. New York: Scientific American.

Hull, D. 1965: The effects of essentialism on taxonomy: Two thousand years of stasis. Part 1. British Journal for the Philosophy of Science, 15, 314-326.

Hull, D. 1988: Science as a process. Chicago: University of Chicago Press.

Inagaki, K. 1990. The effects of raising animals on children's biological knowledge. British Journal of Developmental Psychology, 8, 119-129.

Jacob, F. 1977: Evolution and tinkering. Science, 196, 1161-1166.

Gigerenzer, G. \& Hug, K. 1992: Reasoning about social contracts: Cheating and perspective change. Cognition, 43, 127-171. 
Keil, F. 1994. The birth and nurturance of concepts by domains. In L. Hirschfeld \& S. Gelman (Eds.), Mapping the mind pp. 234-254. New York: Cambridge University Press.

Kelly, M. \& Keil, F. 1985: The more things change...: Metamorphoses and conceptual structure.

Cogntitive science, 9, 403-416.

Knight, N., Sousa, P., Barrett, J. \& Atran, S. in press: Children's attributions of beliefs to humans and God: Cross-cultural evidence. Cognitive Science.

Kroeber, A.L. 1963[1923]: Anthropology. New York: Harcourt, Brace and World.

Kuper, A. 1996: The chosen primate. Cambridge, MA: Harvard university Press.

Leiber, J. 2002: Philosophy, engineering, biology, and history: A vindication of Turing's views about the distinction between the cognitive and physical sciences. Journal of Experimental and Theoretical Artificial Intelligence, 14, 29-37.

Linnaues, C. 1751. Philosophia botanica. Stockholm: G. Kiesewetter.

López, A., Atran, S., Coley, J., Medin, D. \& Smith, E. 1997. The tree of life: Universals of folk-biological taxonomies and inductions. Cognitive Psychology, 32, 251-295.

Lorenz, K. 1966: The role of gestalt perception in animal and human behavior. In L. White (Ed.), Aspects of form. Bloomington: Indiana University Press.

MacDonald, K. 1998: Separation and its discontents: Toward an evolutionary theory of Anti-Semitism. Westport, CT: Praeger.

Marr, D. 1982: Vision. New York: W.H. Freeman.

Maynard Smith, J. 1998: The origin of altruism. Nature, 393, 639-640.

Maynard Smith, J., Burian, R., Kaufman, S., Alberch, P., Campbell, J., Goodwin, B., Lande, R., Raup, D. \& Wolpert, L. 1985: Developmental constraints in evolution. Quarterly Review of Biology, 60, 265-287. Mayr, E. 1982. The growth of biological thought. Cambridge, MA: Harvard University Press.

Medin, D. \& Atran, S. in press: The native mind. Psychological Review.

Medin, D. \& Ortony, A. 1989: Psychological essentialism. In S. Vosniadou \& A. Ortony (Eds.) Similarity and analogical reasoning pp. 179-195. New York: Cambridge University Press. 
Murdock, G. 1949: Social structure. New York: Macmillan.

Pinker, S. 1997: How the mind works. New York: Norton.

Pinker, S. \& Bloom, P. 1990: Natural language and natural selection. Behavioral and Brain Sciences, 13, 707-727.

Povinelli, D. 2000: Folk physics for apes. New York: Oxford University Press.

Povinelli, D. 2001: Chimpanzee theory of mind and folk physics. Paper presented at 'Innateness and Structure of Mind' Workshop, University of Sheffield, November.

Rappaport, R. 1999: Ritual and religion in the making of humanity. Cambridge, UK: Cambridge University Press.

Reeve, H. 2000: Review of 'Unto others.' Evolution and Human Behavior, 21, 65-72.

Romney, A.K., Weller, S. \& Batchelder, W. 1986: Culture as consensus: A theory of culture and informant accuracy. American Anthropologist, 88, 313-338.

Rosch, E., Mervis, C., Grey, W., Johnson, D., \& Boyes-Braem, P. 1976. Basic objects in natural categories. Cognitive Psychology, 8, 382-439.

Ross, N., Medin, D., Coley, J. \& Atran, S. 2003: Cultural and experiential differences in the development of folkbiological induction. Cognitive Development, 18, 25-47.

Sedikides, C. \& Skowronski, J. 1997: The symbolic self in evolutionary context. Personal and Social Psychology Review, 1, 80-102.

Sober, E. \& Wilson, D.S. 1998: Unto others. Cambridge, MA: Harvard University Press.

Solomon, G., Johnson, S., Zaitchik, D. \& Carey, S. 1996. Like father, like son: Young children's understanding of how and why offspring resemble their parents. Child Development, 67, 151-171. Sousa, P., Atran, S. \& Medin, D. 2002: Essentialism in folkbiology: Evidence from Brazil. Journal of Cognition and Culture, 2, 195-203.

Sperber, D. 1994: The modularity of thought and the epidemiology of representations. In L. Hirschfeld \& S. Gelman (Eds.), Mapping the mind pp. 39-67. New York: Cambridge University Press.

Sperber, D. 1996: Explaining culture. New York: Blackwell. 
Sperber, D., Cara, F. \& Girotto, V. 1995: Relevance theory explains the selection task. Cognition, 57, 31 95.

Sperber, D., Premack, D. \& Premack, A., Eds. 1995: Causal cognition. Oxford: Oxford University Press. Thompson, D.W. 1961[1917]: On growth and form. Cambridge, UK: Cambridge University Press.

Thornhill, R. 1997. The concept of evolved adaptation. In G. Bock \& G. Cardew (Eds.), Characterizing human psychological adaptations, pp. 4-13. New York: Wiley.

Tinbergen, N. 1951: The study of instinct. London: Oxford University Press.

Turing, A. 1952: The chemical basis of morphogenesis. Philosophical Transactions of the Royal Society, B 237, 37-72.

Waddington, C. 1959: Canalisation of development and the inheritance of acquired characteristics.

Nature, 183, 1654-1655.

Wallace, A.R. 1889: Darwinism. New York: Macmillan.

Williams, G. 1966: Adaptation and natural selection. Princeton: Princeton University Press.

Williams, G. 1992: Natural selection. New York: Oxford University Press.

Wilson, D.S. 2002: Darwin's cathedral. Chicago: University of Chicago Press.

Wilson, E.O. 1978: On human nature. Cambridge, MA: Harvard University Press.

Institute Jean Nicod Centre National de la Recherche Scientifique and Institute for Social Research The University of Michigan 